\title{
Mental Well-Being Predictivity of Personal Meaning Profile in Various Age Groups
}

\author{
Nur Demirbaş-Çelik \\ Correspondence: Nur Demirbaş-Çelik, Alanya Alaaddin Keykubat University, Education Faculty 07450 Alanya, Antalya, \\ Turkey.
}

Received: August 1, 2018

doi:10.11114/jets.v6i10.3490
Accepted: September 22, 2018

Online Published: September 28, 2018

URL: https://doi.org/10.11114/jets.v6i10.3490

\begin{abstract}
The purpose of this research is to examine which factors of personal meaning profile explain mental well-being in different age stage. Although personal meaning has many different definitions, this research approaches it in seven factors; achievement, relationship, religion, self-transcendence, self-acceptance, intimacy, and fair treatment. The participants in this study were 410 (226 female, 184 male) representing three separate groups (Adolescents, emerging adults, and adults). Whether Personal meaning and mental well-being varied based on age was analyzed via ANOVA. Personal Meaning's predictability of mental well-being was analyzed via multiple regression analysis. First, the mental well-being productivity of personal meaning in the whole group was examined. According to the examination, it was found that all factors except for religion explain mental wellbeing. These factors account for $54 \%$ of the variance. Secondly, multiple regression analysis was done for the personal meaning factors for each group. According to results: Achievement, relationship, and self-transcendence in adolescents; achievement, self-transcendence, self-acceptance, intimacy, and fair treatment in emerging adults; and intimacy, self-transcendence, self-acceptance and fair treatment in adults were significant predictors mental well-being. These factors account for $43 \%$ of total variance in adolescent, $65 \%$ in emerging adults, and $42 \%$ in adults.
\end{abstract}

Keywords: personal meaning, source of meaning, well-being, age stage

\section{Introduction}

Individuals always strive to improve their lives (Mcdonald, Wong, \& Gingras, 2012. Though there are numerous theories about what a good life is, many definitions mention well-being, authenticity, morality, and meaning (Martela, 2017). Happiness and meaning have become subjects often examined together in the recent years. Positive psychology tries to understand people's meaning dynamics while also looking for an answer to the question "what are the concrete sources of meaning in life". Feeding of philosophy, and the work of theoreticians like Adler and Frankl, many approaches to meaning - as it finds it is placed in psychology today - and sources of meaning have come to exist (Corey, 2015). Personal meaning is defined as an individually constructed cognitive system (Wong, 1998). It more often varies from person to person and is created by each individual determining a different source of meaning for themselves (Steger, 2018). Wong's (1998) seven sources of meaning include psychological needs, goals, and cognitive components of meaning. These sources of meaning were determined to be relationships, intimacy, self-transcendence, achievement, self-acceptance, fair treatment, and religion (Wong, 1998; Mcdonald et al.). Relationships involve friendships, memberships in various organizations and clubs; in other words, being a part of society. Intimacy involves sharing personal emotions, desires, thoughts, victories, and defeats, with someone with whom you've formed a meaningful connection. Self-transcendence is a focus on causes and interests beyond themselves, it seeks to further a cause beyond the self and to experience a communion beyond the boundaries of the self through peak experience. Achievement is accepted as the individual's endeavors to reach their goals. Self-acceptance involves the individual behaving as they are, whereas religion involves the person's notions of sacred or divine feelings. Meanwhile, fair treatment is a powerful source of meaning defining and experiencing fairness and respect.

Upon examination, it is noticeable that personal meaning is often evaluated at once with well-being, for example, Emmons (2005) expressed that personal meaning is a building block for well-being. Weinstein, Ryan, \& Deci, (2012) claim that to the link between meaning and well-being and mention that the two may form an antecedent for the one another. Frankl (1985) claim that the experience of having meaning in life is crucial for well-being. In yet another definition of happiness, the meaning is accepted as an elementary component that accompanies pleasure and 
engagement (Seligman \& Csikszentmihalyi, 2000). An analysis of basic definitions of well-being brings up two approaches to defining it; hedonic and eudaimonic (Delle Fave, Brdar, Freire, Vella-Brodrick, \& Wissing, 2011). The hedonia is titled "subjective well-being" and is comprised of positive/negative emotions and life satisfaction (Diener, 1984; Diener, Suh, Lucas, \& Smith, 1999). Eudaimonia, on the other hand, is titled psychological well-being. It involves psychological well-being, self-acceptance, positive relations with others, autonomy, environmental mastery, a purpose in life, and personal growth and is linked to the eudaimonic structure (Ryff, 1989; Ryff \& Keyes, 1995). Besides, the latest definitions of happiness that focus on physical wellness as well have multiplied; a general wellness that includes social, spiritual, emotional and cognitive aspects (Korkut-Owen, Doğan, Demirbaş Çelik, \& Owen, 2016; Myers \& Sweeney, 2004). The definition of happiness that approaches it as positive mental health or mental well-being evaluates the eudaimonic, the hedonic, and wellness all in one; mental well-being here being affective-emotional aspects, cognitive-evaluative dimensions, and involving psychological functioning (Tennant et al., 2007).

Dimensions of the personal meaning profile underline that achievement may be linked to well-being even at early childhood (Ashdown \& Bernard, 2012). Machell, Kashdan, Short, \& Nezlek (2015) found that as the number of positive daily social and achievement experiences increase, so does the understanding of meaning. Also, intrinsic motivation related to achievement is associated with subjective well-being, psychological health and meaning in life (Bailey \& Phillips, 2015). In Turkey, the word achievement evokes academic success; it's very important that students succeed. As an example, a study found that university students in Turkey with a high perception of success tend to have a higher rate of subjective well-being (Tuzgöl-Dost, 2010).

There are studies that indicate that one of the sources of meaning, relationship —or connectedness - predicts subjective well-being (Wei, Howell, \& Iyer, 2014). There are also studies that closely link romantic relationships (Demir, 2008), social skills and the quality of friendships (Demir \& Özdemir, 2010), close relationships with the mother, the father, the best friend, and the romantic partner, etc. (Cenkseven \& Akbaş, 2007; Demir, 2010) with happiness. However, for personal meaning, it is not enough to simply be in a relationship: intimacy that involves social support in a relationship is also highly important (King, Vidourek, Merianos, \& Singh, 2014). However, intimacy is also important in relationships with one's family (Eryılmaz, 2010; Şimşek \& Demir, 2013) in friendships (Demir \& Özdemir, 2010) and in romantic relationships (Demir, 2008).

A meta-study on the link between well-being and religion found a close relationship between religion and mental health (Bonelli \& Koenig, 2013). Another study underlines that religion or spirituality explaining happiness greatly varies based on how people experience religion (Ivtzan, Chan, Gardner, \& Prashar, 2013). A cross-cultural study has discovered that religion and spirituality are important for happiness in all cultures, however, spiritual practice varies based on national context. According to this study, while religious socialization as part of spiritual practice is also linked to well-being, religious socialization is less prevalent (Miu-Chi Lun \& Bond, 2013). An examination of studies done in Turkey has found no meaningful link between happiness and religiosity (Öztürk, Meral, \& Yilmaz, 2017) while another found links between spirituality and happiness (Aydoğan, Özbay, \& Büyüköztürk, 2017).

Self-transcendence is closely related to mental health (Kao, Su, Crocker, \& Chang, 2017; Vago \& Silbersweig, 2012; Van Cappellen, Toth-Gauthier, Saroglou, \& Fredrickson, 2016). Self-transcendence usually isn't approached on its own; it is usually evaluated together with concepts like self-acceptance, self-regulation, and spirituality. For example, Cloninger (2006) mentions self-transcendence and spirituality; he emphasizes that spirituality is a fundamental component of well-being, but it is not the same as religiosity. Koltko-Rivera (2006) claims that Maslow's hierarchy of needs requires self-transcendence as a motivational step to be placed beyond self-actualization. On the other hand, self-acceptance is an indicator of psychological well-being recommended by (Ryff, 1989). Self-acceptance is viewed to be being aware of emotions, and sources of motivation for emotions (Ryff \& Singer, 2008). Finally, fair treatment displays similarities to a dimension of psychological well-being, environmental mastery (Ryff, 1989; Ryff \& Keyes, 1995), which expresses the individual's capacity to effectively direct their life around their own wants and needs. Fair treatment or justice is also a source of happiness for each of the character strengths (Peterson \& Park, 2012).

\subsection{Present Study}

There have been studies done with different age stages, based on the assumption that meaning may change with age (Reker, 2005; Steger, Oishi, \& Kashdan, 2009). In a study from Turkey, however, the presence of meaning showed no meaningful difference between age stages, while the source of meaning actually diminished (Işık \& Üzbe, 2015). In another study, affective meaning displays no difference between young and older people; whereas the cognitive meaning appears to increase with age (Scannell, Allen, \& Burton, 2002). Development theories support that meaning may increase with age, and that the search for meaning takes place during adolescence and emerging adulthood, specifically (Arnett, 2000; Erikson, 1968). A study on sources of meaning showed that these sources don't vary much among younger and older people (Bar-Tur, Savaya, \& Prager, 2001). Macdonald et al. (2012) have found that the dimensions vary based on age, with 
the exception of personal meaning profiles and the relationship dimension. As personal meaning diminishes through the transition from adolescence into adulthood, it once again becomes greater towards old age.

Previous studies on well-being argue that well-being is U-shaped-higher in adolescence and advanced age than in (Blanchflower \& Oswald, 2007). In a study done in Turkey, it was discovered that emerging adults have higher levels of subjective well-being than adults and adolescents (Eryllmaz \& Ercan, 2011). It is thought that this similar pattern will be sufficient for this study as well. In a recent study done by leading happiness research theorists, it was emphasized that while age is a determinant for happiness, a "prosperous happy society with strong social support, income" seems to be the elementary determinant. Sources of meaning may be evaluated through this lens in this study.

In a general sense, the relationship between meaning and subjective and psychological well-being, and quality of life has been established with many most-replicated studies (Steger, 2018). The present study purpose to determine the sources of meaning that explain mental well-being during the periods of adolescence, emerging adulthood, and adulthood. It is expected that different patterns emerge for each age stage. In this context, we assume that achievement will be an indicator of mental well-being especially in the adolescents and emerging adults' groups. The present study also expects that relationship-regarded as a basic psychological need (Deci \& Ryan, 2000), an indicator of psychological well-being (Ryff, 1989) by extension, intimacy will be determinative of mental well-being in all age stages. In terms of religion, the present study examines it more through the aspect of religious practices. The results of the study may indicate that religion and mental well-being are linked; however also that it is not a predictor of happiness. Self-acceptance and self-transcendence-linked to self-actualization, the peak point of Maslow's hierarchy of needs are thought to be linked to mental well-being in all age stages. Finally, most studies one fair treatment tend to be done in workplaces in adults. Finally, while having meaning is positively linked with hope (Yalçın \& Malkoç, 2015) and optimism (Ho, Cheung, \& Cheung, 2010), it is negatively linked to depression and suicide (Tan, Chen, Xia, et al. 2018). For example, a study found that having cognizance of meaning acts as protective factor (Brassai, Piko \& Steger, 2010) against risk behaviors in adolescents. For this reason, it is deemed important to identify sources of meaning that explain well-being. In the context hypotheses of the present study can be summarized as below:

1) Personal sources of meaning in all age stages are predictors of mental well-being.

2) Personal sources of meaning that explain mental well-being vary based on age stages.

\section{Method}

\subsection{Participants}

The participants in this investigation were 410 (226 female, 184 male) representing three separate groups. The ages of the participants ranged between 16 and $59(\overline{\mathrm{x}}=23.6 ;$ SD: 8,06). The participants were separated into three groups based on the stages of adolescence, emerging adulthood, and adulthood. The adolescent's group of 118 high school students (60 female, 58 male) between the ages of $16-18(\overline{\mathrm{x}}=16.9 ; \mathrm{SD}=0.64)$. Emerging adults of 177 university students' ( $107 \mathrm{female}, 70$ male), ages of 19-24 ( $\overline{\mathrm{x}}=21.1 ; \mathrm{SD}=1.54)$. The final group of 115 adults (59 female, 56 male), ages $25-59(\overline{\mathrm{x}}=34.1 ; \mathrm{SD}=7.9)$. The research data was collected via Google Forms. All participants voluntarily participated in the study.

\subsection{Measures}

\subsubsection{Brief Version of the Personal Meaning Profile (BV-PMP)}

The Brief Version of the Personal Meaning Profile (Mcdonald et al., 2012) adapted to Turkish culture by Demirbaş-Çelik (2018). The Personal Meaning Profile (PMP) has 21 items and 7 dimensions. These dimensions are an achievement, relationship, religion, self-transcendence, self-acceptance, intimacy, and fair treatment. All the factors on the scale account for $66.4 \%$ of total variance. As part of the criterion validity analyses, a positive correlation was determined between meaning in life $(r=0.38 ; \mathrm{p}<0.01)$, life satisfaction $(\mathrm{r}=0.45 ; \mathrm{p}<0.01)$, and the life purpose sub-scale $(r=0.49 ; p<0.01)$ with the PMP. The internal consistency coefficient for the whole scale was calculated to be .84 . The internal consistency coefficients for its subscales were determined to be between .64 and .83 . The internal consistency coefficient for the present study was .81 .

\subsubsection{The Warwick-Edinburgh mental well-being scale (WEMWBS)}

The Warwick-Edinburgh Mental Well-Being Scale (WEMWBS) developed by Tennant et al. (2007) to measure both the subjective and psychological well-being of individuals. The scale was adapted into Turkish by Keldal (2015). The scale is made up of 14 items and is scored on a 5 Likert scale. The scale is comprised of a single dimension in order to determine the level of mental well being. The reliability coefficient of the Turkish version of the scale was calculated .89. The internal consistency coefficient for the present study was .90 .

\subsection{Analysis of Data}

The analysis of the data was done in SPSS 20 with multiple regression. Descriptive statistical methods, multivariate analysis of 
variance (MANOVA) and multiple regression analysis were used in the analyses for this study. MANOVA was used in order to examine students' variance by age between their levels of personal meaning and mental well-being. The basic assumptions of regression were tested, and the correlations between the variables were examined using the Pearson Correlation Coefficient. After the multiple regression analysis for the whole of all groups, discrete analyses were done for each group.

\section{Results}

MANOVA results indicate that there is meaningful statistical variance by age in both personal meaning $\mathrm{scores}[\mathrm{F}(2$, $\left.407)=6254.7, \mathrm{p}=0.00, \eta^{2}=.119\right]$ and the mental well-being $\left[\mathrm{F}(2,407)=1094.7, \mathrm{p}=0.00, \eta^{2}=.158\right]$ scores. According to post hoc analyses, all variance between the age group means is significant. Personal meaning means are as follows: $[\overline{\mathrm{x}}=115.7]$ for adults, $[\overline{\mathrm{x}}=104.4]$ for emerging adults, and [ $\overline{\mathrm{x}}=102.3]$ for adolescents; and the MIO means are as follows: $[\bar{x}=58.1]$ for adults, $[\bar{x}=53.2]$ for emerging adults, and $[\bar{x}=57.7]$ for adolescents.

The correlation between the Personal Meaning total score and the scores of its subdimensions and mental well-being (MWI) was calculated using the Pearson Correlation Coefficient (see Table 1). According to results, MWI highly correlates with the total personal meaning $(\mathrm{r}=.68 ; \mathrm{p}<.01)$ and the achievement $(\mathrm{r}=.60 ; \mathrm{p}<.01)$. MWI only correlates with relationship $(\mathrm{r}=.43 ; \mathrm{p}<.01)$, self-transcendence $(\mathrm{r}=.49 ; \mathrm{p}<.01)$, self-acceptance $(\mathrm{r}=.45 ; \mathrm{p}<.01)$, intimacy $(\mathrm{r}=.37 ; \mathrm{p}<.01)$ and fair treatment $(\mathrm{r}=.49 ; \mathrm{p}<.01)$ at an intermediate level, while it correlates with religion $(\mathrm{r}=.22 ; \mathrm{p}<.01)$ at a low level.

Table 1. Correlation between the MWI and dimensions

\begin{tabular}{|c|c|c|c|c|c|c|c|c|c|}
\hline & 1 & 2 & 3 & 4 & 5 & 6 & 7 & 8 & 9 \\
\hline 1. MWI & 1 & & & & & & & & \\
\hline 2. PMP &, $68 * *$ & 1 & & & & & & & \\
\hline 3. Achievement & $60 * *$ &, $70 * *$ & 1 & & & & & & \\
\hline 4. Relationship &, $43 * *$ &, $61 * *$ &, $43 * *$ & 1 & & & & & \\
\hline 5. Religion &, $22 * *$ &, $53 * *$ & $22 * *$ &, $30 * *$ & 1 & & & & \\
\hline 6. Self-transcendence &, $49 * *$ &, $64 * *$ &, $48 * *$ &, $25 * *$ &, $28 * *$ & 1 & & & \\
\hline 7. Self-acceptence &, $45 * *$ &, $64 * *$ &, $42 * *$ &, $32 * *$ &, $19 * *$ &, $31 * *$ & 1 & & \\
\hline 8. Intimacy &, $37 * *$ &, $63 * *$ &, $31 * *$ &, $30 * *$ &, 08 & $22 * *$ &, $34 * *$ & 1 & \\
\hline 9. Fair Treatment & $49 * *$ &, $62 * *$ & $29 * *$ & $25 * *$ & $21 * *$ &, $30 * *$ &, $35 * *$ &, $27 * *$ & 1 \\
\hline
\end{tabular}

$* * \mathrm{p}<, 01$

Multiple regression analysis was conducted by the whole group in order to determine PMP predictiveness of mental well-being. The results are presented in Table 2. According to results, mental well being is explained by achievement, fair treatment, self-transcendence, relationship, self-acceptance, intimacy $[F(7,402)=66,71 ; p<0.01]$, in that order. The religion factor is not among the predictors of mental well-being. These six factors account for $54 \%$ of total variance.

Table 2. Multiple regression analyses PMP dimensions on MWI

\begin{tabular}{|c|c|c|c|c|c|}
\hline & $\mathrm{B}$ & SE & $\beta$ & $\mathrm{t}$ & $\mathrm{p}$ \\
\hline Achievement & 91 & 12 & 32 & 7,30 & , 00 \\
\hline Relationship & ,45 &, 14 &, 13 & 3,21 & 00 \\
\hline Religion &,- 05 & ,08 &,- 02 &,- 59 &, 55 \\
\hline Self-transcendence & ,48 &, 10 &, 18 & 4,57 & 00 \\
\hline Self-acceptence & ,34 & ,13 &, 11 & 2,65 & ,01 \\
\hline Intimacy & ,18 & ,07 & 09 & 2,48 & 01 \\
\hline Fair treatment & ,65 &, 10 &, 25 & 6,72 & ,00 \\
\hline
\end{tabular}

Regression analysis results for the adolescents, emerging adults and adults' group are shown in Table 3. According to this, the dimensions of achievement, self-transcendence, and relationship, respectively, predict mental well-being in adolescents $[\mathrm{F}(7,110)=11,64 ; \mathrm{p}<, 001]$. MWI is predicted by the dimensions of achievement, fair treatment, self-transcendence, self-acceptance, and intimacy in emerging adults $[F(7,169)=45,72 ; p<, 001]$. These five factors account for $65 \%$ of the total variance. According to the results, the fair treatment, self-transcendence, relationship, self-acceptance dimensions, in that order, predict mwi in adults. $[\mathrm{F}(7,107)=10,67 ; \mathrm{p}<, 001]$. These four factors account for $41 \%$ of the total variance.

Table 3. Multiple regression analyses PMP dimensions on MWI for various age groups

\begin{tabular}{|c|c|c|c|c|c|c|c|c|c|c|c|c|}
\hline \multirow[b]{2}{*}{ Factors } & \multicolumn{3}{|c|}{ Adolescent } & \multicolumn{5}{|c|}{ Emerging Adult } & \multicolumn{3}{|c|}{ Adult } & \multirow[b]{2}{*}{$\mathrm{p}$} \\
\hline & SE & $\beta$ & $\mathrm{t}$ & $\mathrm{p}$ & SE & $\beta$ & $\mathrm{t}$ & $\mathrm{p}$ & SE & $\beta$ & $\mathrm{t}$ & \\
\hline Achievement & 0,23 & 0,26 & 2,86 & 0,01 & 0,18 & 0,46 & 7,65 & 0 & 0,24 & 0,08 & 0,93 & 0,36 \\
\hline Relationship & 0,26 & 0,2 & 2,45 & 0,02 & 0,21 & 0,01 & 0,13 & 0,89 & 0,28 & 0,21 & 2,41 & 0,02 \\
\hline Religion & 0,17 & 0 & 0,01 & 0,99 & 0,14 & 0,00 & 0,06 & 0,95 & 0,13 & $-0,07$ & $-0,84$ & 0,4 \\
\hline Self-transcendence & 0,18 & 0,24 & 2,81 & 0,01 & 0,17 & 0,13 & 2,45 & 0,02 & 0,22 & 0,24 & 2,64 & 0,01 \\
\hline Self-acceptence & 0,24 & 0,08 & 1 & 0,32 & 0,19 & 0,12 & 2,18 & 0,03 & 0,25 & 0,18 & 2,12 & 0,04 \\
\hline Intimacy & 0,15 & 0,09 & 1,18 & 0,24 & 0,10 & 0,1 & 2 & 0,05 & 0,15 & 0,01 & 0,16 & 0,87 \\
\hline Fair Treatment & 0,20 & 0,12 & 1,45 & 0,15 & 0,14 & 0,34 & 6,79 & 0,00 & 0,18 & 0,27 & 3,32 & 0 \\
\hline
\end{tabular}




\section{Discussion}

The study pointed out a close link between personal meaning and mental well-being, and that it is explained well by all factors except for religion. Wong (2011) argues that the seven major sources of meaning directly predict well-being. Many studies support the relationship between meaning and happiness (e.g.: Hicks, Trent, Davis, \& King, 2012; Howell, Passmore, \& Buro, 2013). It is peculiar that the results of the study show that the religion factor does not explain mental well-being in Turkey, a collectivist country (Kağitcibasi, 2005) that self-expresses as comprising of religious (Religious Life Research, 2014). One of the reasons for this case might be that the religion-happiness relationship varies based on the individuals' approach to religion (Ivtzan et al., 2013) Examining studies done in Turkey in this regard, one study found no meaningful link between religion and happiness (Öztürk et al., 2017) while another found a link between spirituality and happiness (Aydoğan et al., 2017). A study done with Turkish and Jordanian university students indicates that religiosity predicts life satisfaction, however, this study evaluated the students from the two countries together (Ayten \& Ferhan, 2016). On the other hand, the Miu-Chi Lun \& Bond (2013) states that religious practice and religious understanding-religiosity must be approached separately. All of these reasons might be why the religion factor does not explain mental well-being.

Mental well-being was predicted by achievement, relationship and self-transcendence in adolescents. Because of the fact that adolescents prepare for the university exam and the thing most expected of them is to succeed in the university entry exam, it is pointed out that success seems to explain mental well-being. As adolescence is a stage where friendships and family relationships are very important (Bayraktar, 2007) that relationship is an indicator for mental well-being is in line with the literature (e.g.: Şimşek \& Demir, 2013; Lambert et al., 2010). Intimacy not being an indicator of mental well-being in adolescents stems from adolescent romances being short term, lacking the qualities of a real relationship (Atak \& Tastan, 2012). Adolescence is a period of great ideals and goals. For example, an adolescent may have great ambition to save the world from pollution; therefore, in this context it might be fitting to say that self-transcendence is important for adolescents in terms of happiness. Self-acceptance in adolescents was found to be at a lower level (Mcdonald, et al., 2012); this may be the reason it could not predict mental well-being in adolescents. Studies done in schools indicate that fair treatment by the school is an important protective factor in terms of the academic success and the well-being of their students (Elovainio et al. 2011).

In emerging adults, all factors except relationship and religion predict mental well-being. These results are similar to those of the other groups, with the exception of the relationship factor. While in adolescents it's more important for groups to socialize [e.g., dances, meetups, and parties], emerging adults' relationships tend to involve physical and emotional intimacy more (Atak \& Tastan, 2012). Erikson (1968) has stated that intimacy is the biggest necessity during this period. For this reason, close relationships can be considered to be more important than other relationships in terms of happiness in emerging adults.

Mental well-being was predicted by relationship, self-transcendence, self-acceptance and fair treatment in adults. That achievement is more associated with success in school in Turkey could be the reason why it's not a factor that predicts happiness. Intimacy not being an indicator of happiness in adults is a deviation from the literature (Macdonald et al., 2012). For the adults in this study, relationship emerges as a more predictive factor than intimacy as a source of happiness. The reasons for this could be supported by qualitative studies.

In conclusion, meaning sources having a close link to well-being supports the literature. The religion-well-being relationship must be re-evaluated in new ways through the lens of psychology; happiness must be re-examined through the context of religious understanding-religiosity and religious practice. It's obvious that the number of studies done in Turkey is low and explanatory information they provide is insufficient. In terms of age groups, while achievement predicts mental well-being in adolescent high-school students and emerging adult university students, this is not the case with the adults. The relationship appears as an important source for adolescents and adults; while intimacy is important for emerging adults. Self-transcendence is an indicator of happiness in all age groups. Self-acceptance and fair treatment explain mental well-being in all groups except for adolescents. Considering the negative relationship between personal meaning and depression, stress, and hopelessness Mcdonald et al. (2012) and their contribution to well-being, it is clearly important that services that help develop each source of meaning be provided for the sake of protective mental health.

\section{Implication and Limitation}

Mental well-being and personal meaning profile are higher in adolescents and adults than in the emerging adulthood group. Mental well-being and personal meaning show parallels in variance by age, which stems from the close link between the two concepts. As current psychological and economic theories do not adequately account for the variations in pattern of well-being by age across different parts of the world (Steptoe, Deaton, \& Stone, 2015; Diener, Seligman, Choi, \& Oishi, 2018) this study reveals new information pertaining to meaning and well-being as Turkish culture is 
largely collectivist. As the religion factor does not explain mental well-being for this group, it might be better if studies on this subject approach it in a spiritual context and continue from there. Taking into account that success is important for students' well-being, it's extremely important that effort is made to provide students with an environment wherein every student can experience success. Education policies may be developed in order to create a new perspective on the definition of success. The fact that when examined by age, only either relationship or intimacy explaining mental well-being might stem from the two concepts being largely intertwined in Turkey. As there are few studies done on Turkish culture with regards to self-transcendence, self-acceptance, and fair treatment, new efforts that examine these subjects and their relationship with well-being are necessary. Especially efforts toward increasing self-acceptance in students done by psychological counselors who provide guidance services in schools will obviously contribute to students' well-being. Lastly, it's apparent that culture-specific scale development efforts based on personal meaning and supported by qualitative studies on sources of meaning are feasible. Additionally, comprehensive studies on a meaningful life — an important indicator of a good life in the positive psychology movement of the recent years—which will unearth important related concrete indicators, are necessary.

One of the major limitations of this study is that it is only valid about the work group from which data was collected. Cross-cultural studies may lead to more detailed information. On the other hand, as data could not be collected in different time periods, this study only reflects the current state of the participants; therefore, longitudinal studies are necessary. As this study only utilized the mental well-being scale, it offers less information on psychological and subjective well-being. Despite these limitations, these results offer concrete information about the link between sources of meaning and mental well-being.

\section{References}

Arnett, J. J. (2000). Emerging adulthood: A theory of development from the late teens through the twenties. American Psychologist, 55(5), 469.

Ashdown, D. M., \& Bernard, M. E. (2012). Can explicit instruction in social and Emotional Learning Skills Benefit the Social-Emotional Development, Well-being, and Academic Achievement of Young Children? Early Childhood Education Journal, 39(6), 397-405. https://doi.org/10.1007/s10643-011-0481-x

Atak, H., \& Tastan, N. (2012). Romantic relationships and love. Current Approaches in Psychiatry, 4(4), 520. https://doi.org/10.5455/cap.20120431

Aydoğan, D., Özbay, Y., \& Büyüköztürk, Ş. (2017). Adaptation of the Authentcity Scale and the mediator role of spirituality in the relationship between authenticity and happiness. The Journal of Happiness \& Well-Being, 5(1), $38-59$.

Ayten, A., \& Ferhan, H. (2016). forgiveness, religiousness, and life satisfaction: An empirical study on turkish and jordanian university students, $1(1), 79-84$. https://doi.org/10.12738/spc.2016.1.0006

Bailey, T. H., \& Phillips, L. J. (2016). The influence of motivation and adaptation on students' subjective well-being, meaning in life and academic performance. Higher Education Research \& Development, 35(2), 201-216.

Bar-Tur, L., Savaya, R., \& Prager, E. (2001). Sources of meaning in life for young and old Israeli Jews and Arabs. Journal of Aging Studies, 15(3), 253-269. https://doi.org/10.1016/S0890-4065(01)00022-6

Bayraktar, F. (2007). The importance of parent/peer relationships in positive adolescent development. Turkish Journal of Child and Adolescent Mental Health, 14(3), 157-166.

Blanchflower, D. G., \& Oswald, A. J. (2007). Is Well-being u-shaped over the Life Cycle? The Warwick Economics Research Paper Series (TWERPS) 826, University of Warwick, Department of Economics.

Bonelli, R. M., \& Koenig, H. G. (2013). Mental disorders, religion and spirituality 1990 to 2010: a systematic evidence-based review. Journal of religion and health, 52(2), 657-673. https://doi.org/10.1007/s10943-013-9691-4

Brassai, L., Piko, B. F., \& Steger, M. F. (2011). Meaning in life: Is it a protective factor for adolescents' psychological health? International Journal of Behavioral Medicine, 18(1), 44-51. https://doi.org/10.1007/s12529-010-9089-6

Cenkseven, F., \& Akbaş, T. (2007). Examining the predictors of subjective and psychological well-being of university students. Turkish Psychological Counseling and Guidance Journal, 3(27), 43-46.

Cloninger, C. R. (2006). Fostering spirituality and well-being in clinical practice. Psychiatric Annals, 36(3).

Corey, G. (2015). Theory and practice of counseling and psychotherapy. Nelson Education.

Deci, E. L., \& Ryan, R. M. (2000). The "what" and "why" of goal pursuits: Human needs and the self-determination of behavior. Psychological Inquiry, 11(4), 227-268. https://doi.org/10.1207/S15327965PLI1104_01 
Delle Fave, A., Brdar, I., Freire, T., Vella-Brodrick, D., \& Wissing, M. P. (2011). The Eudaimonic and Hedonic Components of Happiness: Qualitative and Quantitative Findings. Social Indicators Research, 100(2), 185-207. https://doi.org/10.1007/s11205-010-9632-5

Demir, M. (2008). Sweetheart, you really make me happy : Romantic relationship quality and personality as predictors of happiness among emerging adults. Journal of Happiness Studies, 9, 257-277. https://doi.org/10.1007/s10902-007-9051-8

Demir, M. (2010). Close relationships and happiness among emerging adults. Journal of Happiness Studies, 11(3), 293-313.

Demir, M., \& Özdemir, M. (2010). Friendship, need satisfaction and happiness. Journal of Happiness Studies, 11(2), 243-259.

Demirbaş-Çelik, N. (2018). The Brief Personal Meaning Profile (PMP-B): Turkish validity and reliability. YYU Journal of Education Faculty, 15(1), 302-322.

Diener, E. (1984). Subjective well-being. Psychological Bulletin, 95(3), 542. https://doi.org/10.1037/0033-2909.95.3.542

Diener, E., Seligman, M. E., Choi, H., \& Oishi, S. (2018). Happiest people revisited. Perspectives on Psychological Science, 13(2), 176-184.

Diener, E., Suh, E. M., Lucas, R. E., \& Smith, H. L. (1999). Subjective well-being: Three decades of progress. Psychological Bulletin. https://doi.org/10.1037/0033-2909.125.2.276

Elovainio, M., Pietikäinen, M., Luopa, P., Kivimäki, M., Ferrie, J. E., Jokela, J., ... \& Virtanen, M. (2011). Organizational justice at school and its associations with pupils' psychosocial school environment, health, and wellbeing. Social Science \& Medicine, 73(12), 1675-1682.

Emmons, R. A. (2005). Striving for the Sacred: Personal Goals, Life Meaning, and Religion. Journal of Social Issues, 61(4), 731-745. https://doi.org/10.1111/j.1540-4560.2005.00429.x

Erikson, E. (1968). Youth: Identity and crisis (7th ed.). NY: W.W. Norton.

Eryılmaz, A. (2010). Developing a scale about subjective well-being increases strategies for adolescents. Journal of Turkish Psychological Counseling, 33, 81-88.

Eryllmaz, A., \& Ercan, L. (2011). Investigating of the subjective wellbeing based on gender, age and personality. Journal of Turkish Psychological Counseling, 4(39), 139-151.

Frankl, V. E. (1985). Man's search for meaning. Simon and Schuster.

Hicks, J. A., Trent, J., Davis, W. E., \& King, L. A. (2012). Positive affect, meaning in life, and future time perspective: An application of socioemotional selectivity theory. Psychology and Aging, 27(1), 181-189. https://doi.org/10.1037/a0023965

Ho, M. Y., Cheung, F. M., \& Cheung, S. F. (2010). The role of meaning in life and optimism in promoting well-being. Personality and Individual Differences, 48(5), 658-663.

Howell, A. J., Passmore, H. A. A., \& Buro, K. (2013). Meaning in nature: Meaning in life as a mediator of the relationship between nature connectedness and well-being. Journal of Happiness Studies, 14(6), 1681-1696. https://doi.org/10.1007/s10902-012-9403-x

Işık, Ş., \& Üzbe, N. (2015). Personality traits and positive/negative affects: An analysis of meaning in life among adults. Educational Sciences: Theory and Practice, 15(3), 587-595. https://doi.org/10.12738/estp.2015.3.2436

Ivtzan, I., Chan, C. P. L., Gardner, H. E., \& Prashar, K. (2013). Linking religion and spirituality with psychological well-being: Examining self-actualisation, meaning in life, and personal growth initiative. Journal of Religion and Health, 52(3), 915-929. https://doi.org/10.1007/s10943-011-9540-2

Kağitcibasi, C. (2005). Autonomy and relatedness in cultural context. Journal of Cross-Cultural Psychology, 36(4), 403-422. https://doi.org/10.1177/0022022105275959

Kao, C., Su, J. C., Crocker, J., \& Chang, J. (2017). The benefits of transcending self-interest : examining the role of self-transcendence on expressive suppression and well-being. Journal of Happiness Studies, 18(4), 959-975. https://doi.org/10.1007/s10902-016-9759-4

Keldal, G. (2015). Turkish Version of the Warwick-Edinburgh Mental Well-Being Scale: A validity and reliability study. The Journal of Happiness \& Well-Being, 3(1), 103-115. 
King, K. A., Vidourek, R. A., Merianos, A. L., \& Singh, M. (2014). A study of stress , social support, and perceived happiness among college students. The Journal of Happiness \& Well-Being, 2(2), 132-144.

Koltko-Rivera, M. E. (2006). Rediscovering the later version of Maslow's hierarchy of needs: Self-transcendence and opportunities for theory, research, and unification. Review of General Psychology, 10(4), 302.

Korkut-Owen, F., Doğan, T., Demirbaş Çelik, N., \& Owen, D. W. (2016). Development of The Well- Star Scale İyilik Hali Yıldızı Ölçeği ’ nin geliştirilmesi. Journal of Human Sciences, 13(3), 5013-5031. https://doi.org/10.14687/jhs.v13i3.4130

Lambert, N. M., Stillman, T. F., Baumeister, R. F., Fincham, F. D., Hicks, J. a., \& Graham, S. M. (2010). Family as a salient source of meaning in young adulthood. The Journal of Positive Psychology, 5(5), 367-376. https://doi.org/10.1080/17439760.2010.516616

Machell, K. A., Kashdan, T. B., Short, J. L., \& Nezlek, J. B. (2015). Relationships between meaning in life, social and achievement events, and positive and negative affect in daily Life. Journal of Personality, 83(3), 287-298. https://doi.org/10.1111/jopy.12103

Martela, F. (2017). Can good life be measured? The dimensions and measurability of a life worth living. In metrics of subjective well-being: Limits and improvements (pp. 21-42). Springer, Cham.

Mcdonald, M. J., Wong, P. T. P., \& Gingras, D. T. (2012). Development of a Brief Version of the Personal Meaning Profile. In P. T. P. Wong (Ed.), The human quest for meaning: A handbook of psychological research and clinical applications (2nd ed., pp. 357-382). NY: Taylor \& Francis Group.

Miu-Chi Lun, V., \& Bond, M. H. (2013). Examining the relation of religion and spirituality to subjective wellexamining the relation of religion and spirituality to subjective well-being across national cultures. Psychology of Religion and Spirituality, 5(4), 1941-1022. https://doi.org/10.1037/a0033641

Myers, J. E., \& Sweeney, T. J. (2004). The indivisible self: An evidence-based model of wellness. Journal of Individual Psychology, 60, 234-244.

Öztürk, L., Meral, İ. G., \& Yilmaz, S. S. (2017). The relationship between Happiness and Religiosity for Undergraduate Students : A case of Kırıkkale University. Journal of Academic Approaches, 8(1), 23-39.

Peterson, C., \& Park, N. A. N. S. O. O. K. (2012). Character strengths and the life of meaning. The human quest for meaning: Theories, research, and applications, 277-295.

Reker, G. T. (2005). Meaning in life of young, middle-aged, and older adults: Factorial validity, age, and gender invariance of the Personal Meaning Index (PMI). Personality and Individual Differences, 38(1), 71-85. https://doi.org/10.1016/j.paid.2004.03.010

Religious Life Research-Türkiye'de dini hayat araştırması. (2014). Ankara: Diyanet İşleri Başkanlı̆̆ı Yayınları. Retrieved from: http://www2.diyanet.gov.tr/StratejiGelistirme/Afisalanlari/dinihayat.pdf 27.07.2018

Ryff, C. D. (1989). Happiness is everything, or is it? Explorations on the meaning of psychological well-being. Journal of Personality and Social Psychology, 57(6), 1069-1081. https://doi.org/10.1037/0022-3514.57.6.1069

Ryff, C., \& Keyes, C. L. (1995). The structure of psychological well-being revisited. Journal Od Personality and Social Psychology, 69(4), 719-727.

Ryff, C., \& Singer, B. H. (2008). Know thyself and become what you are: a eudaimonic approach to psychological well-being. Journal of Happiness Studies, 9(13), 13-39. https://doi.org/10.1007/s10902-006-9019-0

Scannell, E. D., Allen, F. C., \& Burton, J. (2002). Meaning in life and positive and negative well-being. North American Journal of Psychology, 4(1), 93.

Seligman, M. E. P., \& Csikszentmihalyi, M. (2000). Positive psychology: An introduction. American Psychologist, 55(1), 5-14. https://doi.org/10.1037//0003-066X.55.1.5

Şimşek, Ö. F., \& Demir, M. (2013). parental support for basic psychological needs and happiness: the importance of sense of uniqueness. Social Indicators Research, 112(3), 661-678. https://doi.org/10.1007/s11205-012-0075-z

Steger, M. F. (2018). Meaning and well-being. In E. Diener, S. Oishi, \& L. Tay (Eds.), Handbook of well-being. Salt Lake City, UT: DEF Publishers.

Steger, M. F., Oishi, S., \& Kashdan, T. B. (2009). Meaning in life across the life span: Levels and correlates of meaning in life from emerging adulthood to older adulthood. The Journal of Positive Psychology, 4(1), 43-52. https://doi.org/10.1080/17439760802303127 
Steger, M. F., Oishi, S., \& Kashdan, T. B. (2009). Meaning in life across the life span : Levels and correlates of meaning in life from emerging adulthood to older adulthood emerging adulthood to older adulthood, (908234135). https://doi.org/10.1080/17439760802303127

Steptoe, A., Deaton, A., \& Stone, A. A. (2015). Subjective wellbeing, health, and ageing. The Lancet, 385(9968), 640-648.

Tan, L., Chen, J., Xia, T., \& Hu, J. (2018, April). Predictors of Suicidal Ideation Among Children and Adolescents: Roles of Mental Health Status and Meaning in Life. In Child \& Youth Care Forum, 47, 2, 219-231. https://doi.org/10.1007/s10566-017-9427-9

Tennant, R., Hiller, L., Fishwick, R., Platt, S., Joseph, S., Weich, S., Parkinson, J., Secker, J., \& Stewart-Brown, S. (2007). The Warwick-Edinburgh mental well-being scale (WEMWBS): Development and UK validation. Health and Quality of Life Outcomes, 5(1), 50-63. https://doi.org/10.1186/1477-7525-5-63

Tuzgöl-Dost, M. (2010). An examination of subjective well-being and life satisfaction of students attending to universities in South Africa and Turkey. Education and Science, 35(158), 75-89.

Vago, D. R., \& Silberswei, D. A. (2012). Self-awareness, self-regulation, and self-transcendence (S-ART): a framework for understanding the neurobiological mechanisms of mindfulness. Frontiers in Human Neuroscience, 6, 296.

Van Cappellen, P., Toth-Gauthier, M., Saroglou, V., \& Fredrickson, B. L. (2016). Religion and well-being: The mediating role of positive. Journal of Happiness Studies, 17, 485-505. https://doi.org/10.1007/s10902-014-9605-5

Wei, J., Howell, R. T., \& Iyer, R. (2014). Engagement with natural beauty moderates the positive relation between connectedness with nature and psychological well-being. Journal of Environmental Psychology, 38, 55-63. https://doi.org/10.1016/j.jenvp.2013.12.013

Weinstein, N., Ryan, R. M., \& Deci, E. L. (2012). Motivation, meaning, and wellness: A self-determination perspective on the creation and internalization of personal meaning and life goals. In P. T. Wong (Ed.), The human quest for meaning: A handbook of psychological research and clinical applications (2nd ed., pp. 81-107). NY: Taylor \& Francis Group.

Wong, P. T. (1998). Implicit theories of meaningful life and the development of the personal meaning profile. In P. Wong \& P. S. Fry (Eds.), The human quest for meaning: A handbook of psychological research and clinical applications. (pp. 111-140). Mahwah, NJ: Lawrence Erlbaum.

Wong, P. T. (2011). Positive psychology 2.0: Towards a balanced interactive model of the good life. Canadian Psychology, 52(2), 69-81.

Yalçın, İ., \& Malkoç, A. (2015). The relationship between meaning in life and subjective well-being: Forgiveness and hope as mediators. Journal of Happiness Studies, 16(4), 915-929.

\section{Copyrights}

Copyright for this article is retained by the author(s), with first publication rights granted to the journal.

This is an open-access article distributed under the terms and conditions of the Creative Commons Attribution license which permits unrestricted use, distribution, and reproduction in any medium, provided the original work is properly cited. 